\title{
Desastre Ambiental da Barragem de Fundão, Mg - Análise de Impactos Socioambientais
}

\author{
Brigiti Bandini'; Flávia Constantino da Vitória²; Elenice Rachid da Silva³; Josimar Ribeiro de \\ Almeida ${ }^{l}$ \\ \bpcll@hotmail.com
}

1. Universidade do Estado do Rio de Janeiro, RJ. 2. Universidade Federal Fluminense, Niterói, RJ. 3. Universidade Federal do Rio de Janeiro, RJ

\section{Histórico do Artigo:}

Recebido em: 19 de fevereiro de 2019 Aceito em: 18 de novembro de 2019 Publicado em: 28 de dezembro de 2019

Resumo: 0 rompimento da barragem do Fundão, localizada no município de Mariana (MG), foi responsável pelo maior desastre ocasionado por uma empresa de mineração, sendo considerada a maior catástrofe ambiental já ocorrida no Brasil. Foram lançados no meio ambiente, conforme apresentado no Laudo Preliminar do IBAMA (2015), cerca de 34 milhões de $\mathrm{m}^{3}$ de rejeito de mineração de ferro, pela mineradora Samarco - empresa associada a empresa Vale do Rio Doce e a empresa britânica BHP Billiton. Foram atingidos rios, córregos e vegetações, além do soterramento de residências e propriedades deixando muitas famílias desabrigadas, sem seus meios de subsistência, e fragilizadas pelos óbitos de entes próximos. Em poucas horas, após o rompimento da barragem, a lama chegou ao rio Doce, provocando aumento na turbidez da água e promovendo a morte de milhares de peixes e outros animais. Neste trabalho foi feita uma busca bibliográfica dos principais impactos ambientais gerados pelo desastre, separados em três categorias de danos: ambiental, socioambiental e humano, bem como os planos de recuperação de cada um. Os resultados mostraram que os impactos tiveram grande complexidade, que muitas áreas serão impossibilitadas de retornarem ao seu estado anterior e alguns planos demorarão longos anos para serem concluílos.

Palavras-chave: Desastre, Recuperação, Danos ambientais, Impactos Socioambientais.

\section{Environmental Disaster of Fundão Dam, Mg - Analysis of Socio-Environmental Impacts}

\begin{abstract}
The disruption of the Fundão dam, located in the municipality of Mariana (MG), was responsible for the biggest disaster caused by a mining company, being considered the largest environmental catastrophe ever occurred in Brazil. About 34 million $\mathrm{m}^{3}$ of iron ore tailings were released into the environment, according to IBAMA's Preliminary Report (2015), by mining company Samarco - a company associated with Vale do Rio Doce and British company BHP Billiton. Rivers, streams and vegetation were hit, as well as the burial of homes and properties leaving many families homeless, without their means of subsistence, and weakened by the deaths of close ones. Within hours, after the dam broke, the mud reached the Doce River, causing increased turbidity of the water and causing the death of thousands of fish and other animals. In this work a bibliographic search of the main environmental impacts generated by the disaster was made, separated in three categories of damages: environmental, social and environmental and human, as well as the recovery plans of each one. The results showed that the impacts were highly complex, that many areas will be unable to return to their previous state and some plans will take long years to complete.
\end{abstract}

Keywords: Disaster, Recovery, Environmental damage, Socio-environmental Impacts. 


\section{Desastre Ambiental del Barragem de Fundão, Mg - Análisis de Impactos Socioambientales}

Resumen: La interrupción de la presa de Fundão, ubicada en el municipio de Mariana (MG), fue responsable del mayor desastre causado por una empresa minera, siendo considerada la mayor catástrofe ambiental jamás ocurrida en Brasil. De acuerdo con el Informe preliminar de IBAMA (2015), la compañía minera Samarco, una compañía asociada con Vale do Rio Doce y la compañía británica BHP Billiton, liberaron al medio ambiente cerca de 34 millones de $\mathrm{m}^{3}$ de relaves de mineral de hierro. Se vieron afectados ríos, arroyos y vegetación, así como el entierro de casas y propiedades que dejaron a muchas familias sin hogar, sin sus medios de subsistencia, y debilitadas por la muerte de personas cercanas. En cuestión de horas, después de que se rompió la presa, el lodo llegó al río Doce, causando una mayor turbidez del agua y causando la muerte de miles de peces y otros animales. En este trabajo se realizó una búsqueda bibliográfica de los principales impactos ambientales generados por el desastre, separados en tres categorías de daños: ambientales, sociales y ambientales y humanos, así como los planes de recuperación de cada uno. Los resultados mostraron que los impactos fueron muy complejos, que muchas áreas no podrán volver a su estado anterior y que algunos planes tardarán muchos años en completarse.

Palabras clave: Desastre, Recuperación, Daños ambientales, Impactos Socioambientales.

\section{INTRODUÇÃO}

No dia 5 de novembro de 2015 o maior desastre ambiental do Brasil aconteceu através do rompimento da barragem de Fundão, pertencente à mineradora Samarco S/A, no município de Mariana, no Estado de Minas Gerais, despejando, aproximadamente, trinta e quatro milhões de $\mathrm{m}^{3}$ de rejeitos de mineração de ferro diretamente no meio ambiente e pela cidade, e 0 restante do rejeito, 16 milhões de $\mathrm{m}^{3}$, foram carreados aos poucos se alastrando por $22 \mathrm{~km}$ até a foz do rio Doce, em direção ao mar chegando ao município de Linhares, área litorânea do Espírito Santo. Junto com a lama, a destruição de cidades, casas, rios, vegetações, fauna e vidas humanas, ou seja, ecossistemas inteiros numa escala micro e macrorregional. Muitos desses danos são caracterizados como irreparáveis.

\footnotetext{
"Inicialmente, esse rejeito atingiu a barragem de Santarém logo a jusante, causando seu galgamento e forçando a passagem de uma onda de lama por $55 \mathrm{~km}$ no rio Gualaxo do Norte até desaguar no rio do Carmo. Neste, os rejeitos percorreram outros $22 \mathrm{~km}$ até seu encontro com o rio Doce. Através do curso deste, foram carreados até a foz no 0ceano Atlântico, chegando no município de Linhares, no estado do Espírito Santo, em 21/11/2015, totalizando 663,2 km de corpos hídricos diretamente impactados" (IBAMA, LAUDO TÉCNIC0 PRELIMINAR, 2015, página 3).
}

De acordo com Laudo Técnico Preliminar do IBAMA, de novembro de 2015, a barragem do Fundão, teve seu rompimento classificado, quanto a evolução, como súbito devido à velocidade que o processo evoluiu e a violência dos eventos adversos. A barragem continha 50 milhões de $\mathrm{m}^{3}$ de rejeitos classificado como não perigoso e não inerte para ferro e manganês. 
A bacia do rio Doce está inserida no bioma de Mata Atlântica, que possui grande biodiversidade e alto índice de endemismo, assim como também abriga o maior índice demográfico no território brasileiro. 0 Impacto ambiental na região atingida pelo rompimento da barragem do Fundão foi de grande proporção, tendo em vista o volume de rejeito vazado, causando o soterramento e devastando a mata ciliar e espécies arbóreas. Outro aspecto negativo, apontado no Laudo Técnico Preliminar do IBAMA (2015), é o potencial do rejeito de minério de ferro em afetar, a médio e longo prazo o solo, desestruturando sua estrutura química e afetando o pH, impactando diretamente espécies que vivam no local. 0s impactos nos corpos hídricos contidos na região atingida e a fauna aquática também foram de grande magnitude. Conforme apresentado no laudo do IBAMA, de 2015, a extensão de corpos d'água atingidos pelos rejeitos foi de mais de $600 \mathrm{~km}$. Esses fatos podem modificar aspectos do bioma local e promover o estabelecimento de ecossistemas diferentes na região atingida.

No presente trabalho, serão abordados alguns dos principais impactos ambientais gerados por esse desastre através de revisão sistemática com área de abrangência desde os municípios próximos à barragem, até os mais distantes que foram impactados. 0 Governo de Minas Gerais apresentou, através do Relatório: Avaliação dos efeitos e desdobramentos do rompimento da Barragem de Fundão em Mariana - MG (2016), a lista de municípios atingidos, contabilizando um total de 35 cidades no Estado de Minas Gerais.

Os danos ocasionados foram separados em ambientais, contemplando à flora, fauna, sistemas de rios e lagos; danos socioambientais, como patrimônios públicos, imóveis, disponibilidade de água, etc; e danos humanos, como mortes, doenças, entre outras. 0 objetivo do trabalho é reunir as informações sobre os impactos documentados após a ocorrência do desastre, até as mais recentes, bem como os planos de recuperação e suas dificuldades de implementação.

\section{MATERIAL E MÉTODOS}

0 desastre ocorreu no Município de Mariana, em Minas Gerais, às 15:30 horas do dia 5 de novembro de 2015. A empresa SAMARC0 Mineração S.A, responsável pelo ocorrido, foi fundada no ano de 1977, atuando como uma empresa privada da Vale S.A. e BHP Billiton Brasil Ltda, e é atuante no segmento de mineração. Seu principal produto final são pelotas de minério de ferro comercializadas para indústrias de siderúrgica. 
0s impactos gerados pelo rompimento da barragem se estenderam desde o município de Mariana, local do acidente, até ao longo dos quase $700 \mathrm{~km}$ de comprimento do rio Doce, chegando aos Estados de Espírito Santo e Bahia. Os impactos também ultrapassaram as barragens de Santarém, percorrendo $55 \mathrm{~km}$ no rio Gualaxo do Norte até o rio do Carmo, em Minas Gerais.

0 presente trabalho apresenta dados referentes aos impactos gerados por essa catástrofe, divididos do seguinte modo: danos ambientais, divididos em solo, rios e lagos, flora e fauna; danos socioambientais, divididos em disponibilidade de água, patrimônio público e privado, economia; e danos humanos, divididos em mortes, doenças e danos psicológicos. Cada um reunindo informações de diversos órgãos do governo.

\section{RESULTADOS E DISCUSSÃ0}

0s resultados obtidos a partir da metodologia utilizada são os seguintes para cada uma das categorias apresentadas:

\section{Danos ambientais}

0 documento científico intitulado "Laudo Técnico Preliminar: Impactos ambientais decorrentes do desastre envolvendo o rompimento da barragem de Fundão, em Mariana, Minas Gerais" foi elaborado pelo IBAMA (IBAMA, 2015). A partir de dados coletados desse documento, separamos os impactos ambientais gerados nas seguintes categorias: solo, rios e lagos, flora e fauna.

\section{Solo}

Os resultados de uma análise de teores totais de elementos químicos do solo apontam valores inferiores aos adotados como referência para avaliação da contaminação de metais no solo, de acordo com a Resolução no 420 do CONAMA (2009). Mas, ainda assim, materiais inertes sem matéria orgânica, como os rejeitos de mineração de ferro, têm potencial para atingir o solo ao longo do tempo, causando desestruturação química e afetando o Ph do solo. Essa modificação poderá afetar as espécies que habitavam o local, podendo também modificar a vegetação nativa, impactando assim o ecossistema da região (LOPES, 2016).

A camada com baixa porosidade formada pelo depósito de lama composta de rejeitos pode fazer com que o solo fique impermeabilizado e sem nenhum tipo de matéria orgânica. Sem chance de reconstrução de modo natural da vegetação (LOPES, 2016). 
Os resultados encontrados com valores muito baixo de nutrientes no solo, a baixa concentração de argila e valores de pH extremamente ácidos, mostram que a fertilidade do solo está altamente comprometida. Em diversas áreas atingidas constatou-se a presença de processos erosivos (EMBRAPA, 2010).

\section{Rios e lagos}

Mais de $600 \mathrm{~km}$ de cursos d'água foram afetados e contaminados pela lama de resíduos da mineração segundo o documento do IBAMA.

0 rio Gualaxo do Norte, o rio Carmo e o rio Doce foram afetados pelos rejeitos que foram carregados até o Oceano Atlântico, chegando ao estado do Espírito Santo, somando 663,2 km de corpos hídricos diretamente impactados.

A contaminação se deu pela lama com altos níveis de concentração de diversos metais pesados, como ferro, cádmio, arsênio, chumbo, cobre, entre outros. De acordo com informação técnica do IBAMA, vários pontos de coleta ao longo do rio Doce apresentaram níveis de concentração de metais pesados acima dos limites permitidos para as águas de classe I, conforme definido pela resolução 357, de 17 de março de 2005, do CONAMA. Além disso, pesquisadores apontam que muitos metais que não se encontram regulamentados pela ANVISA também apresentam níveis elevados de concentração nos organismos (Informação Técnica nº 0032016 - IBAMA).

Sobre os danos causados ao conjunto de espécies de peixes que habitavam aquela região hidrográfica (ictiofauna), foi identificado ao longo do trajeto do rio Doce um elevado índice de mortandade desses peixes. Os sedimentos que fazem parte dos rejeitos fizeram com que o nível de turbidez da água se elevasse, houve o colabamento das brânquias dos peixes que morreram por asfixia. Essa turbidez impede a entrada de luz solar na água, o que torna a fotossíntese inviável, e consequentemente causa a morte dos produtores primários aquáticos, como fitoplâncton, perifíton, e macrófitas aquáticas submersas. Assim podemos notar que houve um impacto grande em toda a cadeia trófica daquela região hidrográfica.

Diante de um quadro de destruição, contaminação e de incertezas, o Rio Doce precisa de medidas que minimizem esses danos causados ao ecossistema. A adoção de Planos de Recuperação de Áreas Degradadas - PRAD’s, além de realizar o acompanhamento ambiental são medidas que, a médio e longo prazo, tendem a proporcionar a recuperação do rio Doce (Grupo da Força-Tarefa, 2016). 


\section{Flora}

A vegetação ao longo de regiões hidrográficas é extremamente importante para a manutenção da biodiversidade local, atenuando a erosão do solo, regularizando os fluxos hídricos e impedindo o processo de assoreamento dos cursos. (BRASIL, 2015)

Matas ciliares remanescentes foram devastadas. A lama imediatamente soterrou os indivíduos de menor porte do sub-bosque e suprimindo indivíduos arbóreos. A consolidação da lama sobre o chão das matas compromete seus bancos de sementes e consequentemente sua resiliência e sucessão.

\footnotetext{
"0s rejeitos de mineração de ferro também têm potencial para afetar o solo ao longo do tempo por se tratarem de material inerte sem matéria orgânica, causando desestruturação química e afetando $0 \mathrm{pH}$ do solo. Tal alteração dificultará a recuperação e o desenvolvimento de espécies que ali viviam, podendo modificar, a médio e longo prazos, a vegetação local, com o estabelecimento de ecossistemas diferentes dos originais" (IBAMA, LAUD0 TÉCNIC0 PRELIMINAR, 2015, página 3).
}

Certamente, trechos com baixa ou nenhuma capacidade de resiliência necessitarão de Planos de Recuperação de Áreas Degradadas - PRAD, a serem executados a longo prazo. Em ambas as situações - PRADs x Regeneração Natural - 0 monitoramento ambiental deverá ser constante até a completa regeneração do ambiente (BRASIL, 2015, p. 11).

\section{Fauna}

Os primeiros danos a se observar foram a completa aniquilação dos anfíbios, mamíferos e animais de pequeno porte, cujos habitats estabelecidos às margens dos rios foram soterrados pelos resíduos. Morreram também animais domésticos e de produção (Grupo da Força-Tarefa, 2016).

Com a avalanche de lama muitos peixes morreram, além disso, uma parte também foi afetada pela turbidez da água que impede a penetração da luz solar, causando morte aos peixes por asfixia. Podendo ser causada uma extinção de espécies endêmicas naquele local (Grupo da Força-Tarefa, 2016).

Aves aquáticas podem ser afetadas ao se alimentar de peixes mortos e contaminados, podendo prejudicar sua reprodução, com a má formação dos ovos e comprometendo suas estruturas reprodutivas (Grupo da Força-Tarefa, 2016).

Por fim, o laudo do IBAMA informa que, definitivamente, houve impacto sobre as espécies nativas da fauna. Principalmente por causar a perda do hábitat natural desses animais ou por comprometer sua reprodução. 
Para que haja uma medida de mitigação é necessário recuperar outras condições ambientais, como condições de solo, e a restauração dos ambientes vegetais representativos da mata local.

\section{Danos socioambientais}

A partir dos dados informados pelos órgãos IBAMA e IGAM acerca dos impactos socioambientais gerados, separamos nas seguintes categorias: disponibilidade de água, patrimônio público e privado e economia.

\section{Disponibilidade de água}

A qualidade da água dos rios foi imediatamente afetada pela onda de rejeitos. Houve contaminação com metais que tornaram a água imprópria para consumo por tempo indeterminado, interrompendo o abastecimento de água nos municípios afetados. Sendo necessária a adoção de sistemas alternativos de captação para as comunidades que dependiam do abastecimento pelas águas do Rio Doce (Grupo da Força-Tarefa, 2016).

Um encarte feito em 2016 pelo governo de Minas Gerais mostra a situação da qualidade da água um ano após o desastre. Foi percebido que a maioria dos metais presentes da água estava acima do limite legal para os parâmetros de turbidez.

A recuperação da qualidade da água será um processo lento, e que alguns eventos como chuvas e ações antrópicas poderão resolver o problema. Assim, o monitoramento dessa região afetada deve ser constante (Grupo da Força-Tarefa, 2016).

\section{Patrimônio público e privado}

0 desastre gerou uma perda de patrimônio da população como casas e comércios e patrimônio públicos e históricos.

Conforme descrito de no relatório de Avaliação dos efeitos e desdobramentos do rompimento da Barragem de Fundão em Mariana (MG, 2016), três igrejas foram atingidas. A Capela São Bento, que foi levada pela lama, e Capela de Nossa Senhora das Mercês, que serviu de abrigo e teve peças sacras retiradas pelo Ministério Público, ambas no município de Bento Rodrigues, e a Capela de Santo Antônio, localizada em Paracatu de Baixo, que foi também atingida pela lama.

A Constituição Federal estabelece a responsabilidade civil objetiva do Estado pelos danos causados às pessoas e seu patrimônio. Essa responsabilidade civil objetiva implica que não se 
exige prova da culpa do agente público para que a pessoa lesada tenha direito à indenização. Basta a demonstração do nexo de causalidade entre o dano sofrido e a ação ou omissão das autoridades responsáveis (NUNES Rizzatto, 2015).

0s moradores de Mariana receberam suporte da Defesa Civil de MG quanto ao abrigo, bens materiais como colchões, kit higiênico e de limpeza e cestas básicas, abastecimento de água com carros pipa. 0 órgão também foi responsável por realizar a comunicação entre as prefeituras de Mariana, Barra Longa e Rio Doce com a empresa Samarco, com finalidade de implementar ações de respostas. 0s moradores também receberam doações humanitárias de diversas 0NGs e Estados do Brasil.

\section{Economia}

A economia na região foi afetada de diversas formas, desde as atividades agropecuárias que sofreram impacto devido aos estragos pela onda de lama (com a impossibilidade do uso da água para irrigação de lavouras e para o uso do gado) até pequenos comércios locais. A interrupção da produção mineradora no município de Mariana também foi uma forma de afetar a economia.

"Houve a redução do fluxo de passageiros nas balsas que atravessam o Rio Doce em até $70 \%$, devido ao mau cheiro e ao medo, além de registros de defeitos nos motores por causa da lama, afetando assim a economia local” (Grupo da força-tarefa, 2016).

A atividade com maior prejuízo econômico privado foi a indústria, somando R\$ 208.290.000,00, com destaque para Belo Oriente em decorrência da paralisação temporária da Cenibra Papel e Celulose, por impossibilidade de captação de água. (Grupo da Força-Tarefa, 2016).

Observa-se assim a necessidade de medidas de curto prazo (sustentação da economia sem a retomada da mineração), médio prazo (retomada da mineração em bases sustentáveis) e longo prazo (investimentos para tornar a economia regional mais diversificada).

\section{Danos humanos}

Os danos humanos foram classificados em mortes, doenças e danos psicológicos e foram obtidos a partir de Secretaria de Estado de Desenvolvimento Regional de Minas Gerais, IBAMA e FIOCRUZ.

\section{Mortes}


0 povoado de Bento Rodrigues, com cerca de 200 casas e 600 moradores, foi quase totalmente coberto pela lama, com perda de infraestrutura pública e bens privados, necessitando de relocação. Seis outras comunidades foram parcialmente afetadas pela lama. 0 total de mortos atingidos pela barragem foram 19. 0 número total de afetados nos municípios mais próximos à barragem é bem maior: 10.482 (GRUP0 DA FORÇA-TAREFA, 2016) (tabela 1).

Tabela 1. Dados de danos humanos de formulários municipais entregues à força-tarefa de Minas Gerais.

\begin{tabular}{|c|c|c|c|c|c|c|c|c|}
\hline \multirow{2}{*}{ 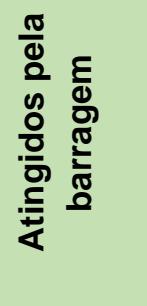 } & \multicolumn{8}{|c|}{ DANOS HUMANOS DIRETOS E INDIRETOS } \\
\hline & 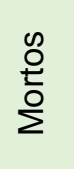 & $\begin{array}{l}\text { 음 } \\
\text { 읗 } \\
\text { एँ }\end{array}$ & 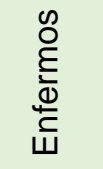 & 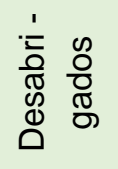 & 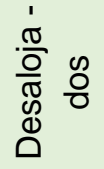 & 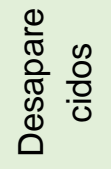 & 告 & 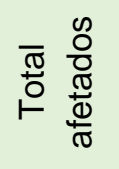 \\
\hline Mariana & 17 & 6 & 225 & 504 & 308 & 2 & 2807 & 3869 \\
\hline $\begin{array}{l}\text { Barra } \\
\text { Longa }\end{array}$ & & 250 & 55 & 140 & 400 & & 4900 & 5745 \\
\hline $\begin{array}{l}\text { Rio } \\
\text { Doce }\end{array}$ & & & & & 3 & & 360 & 363 \\
\hline $\begin{array}{l}\text { Santa C. } \\
\text { Es. }\end{array}$ & & & & & 5 & & 500 & 505 \\
\hline Total & 17 & 256 & 280 & 644 & 716 & 2 & 8567 & 10482 \\
\hline
\end{tabular}

Obs: de acordo com a defesa civil, a categoria outros afetados são aqueles prejudicados de alguma forma pelo desastre direta ou indiretamente.

Fonte: GRUP0 DA FORÇA-TAREFA, 2016.

\section{Doenças}

De acordo com o IBAMA, os locais atingidos tiveram uma interrupção de serviços de vigilância em saúde, epidemiológica, sanitária, ambiental e saúde do trabalhador. Estes locais podem se tornar pontos de vetores de doenças como dengue, Chikungunya, Zicka Vírus, Esquistossomose, Chagas, Leishmaniose e problemas com animais peçonhentos, conforme apontado também pela FIOCRUZ (Força-Tarefa, 2016).

Devido à contaminação das águas, apesar de alertada a população e da criação de novos sítios de captação de água em alguns locais, a população afetada corre o risco de contaminação por metais pesados, gerando sérios riscos à saúde (Força-Tarefa, 2016). 
A elaboração de projetos de construção de sistemas alternativos de captação e adução de água e programas de melhoria nas estações de tratamento de águas nos municípios que captam água do rio Doce está sendo implementados pela Fundação Renova. Há também um programa de monitoramento qualitativo e quantitativo sistemático (PMQQS) de água e de sedimentos, de caráter permanente, abrangendo a avaliação de riscos toxicológicos e ecotoxicológicos pela mesma fundação.

\section{Danos psicológicos}

A população afetada teve toda a sua vida drasticamente modificada, tendo perdido vários bens pessoais, a fonte de sustento e muitos, parentes e pessoas queridas, bem como a paisagem do local em que viviam. Toda essa situação gerou abalo psicológico em muitas pessoas. A insegurança também tomou conta da população, devido ao medo de águas contaminadas e também o medo de outras barragens que existem no mesmo complexo que a do Fundão, que são as de Germano e Santarém, serem rompidas. Ambas têm seus níveis de segurança abaixo do nível estipulado pelas normas de segurança de barragens (Força-Tarefa, 2016).

Segundo declarações da empresa Samarco, tem sido ofertada assistência psicológica para a população, considerada pela empresa, como diretamente afetada, o que é atestado pela prefeitura de Mariana.

\section{Planos de recuperação}

De acordo com a Resolução CONAMA n001 (1986), impacto ambiental é definido como:

Art. 1. [...] qualquer alteração das propriedades físicas, químicas e biológicas do meio ambiente, causadas por qualquer forma de matéria ou energia resultante das atividades humanas que, direta ou indiretamente afetam:

I - a saúde, a segurança e o bem-estar da população;

II - as atividades sociais e econômicas;

III - a biota;

IV - as condições estéticas e sanitárias do meio ambiente;

$\mathrm{V}$ - a qualidade dos recursos ambientais.

A partir dos resultados obtidos, podemos observar a magnitude dos danos causados pelo maior desastre ambiental da história do Brasil. Estima-se que 80\% dos impactos ambientais são irreversíveis para a flora e fauna de um determinado local afetado. Toda e qualquer atividade humana de caráter exploratório de recursos naturais deixa cicatrizes no meio ambiente, 
irreversíveis ou reversíveis, mas a área explorada não volta a ser totalmente o mesmo ambiente que era antes (MUCELIN E BELLINI, 2008). Devido à grande magnitude destes impactos ambientais, o rio Doce e suas proximidades afetadas nunca mais voltarão ao seu estado anterior.

Para tentar resgatar ao máximo as condições ambientais das regiões afetadas para seu estado anterior, o IBAMA exigiu das empresas responsáveis a apresentação e implementação de planos de restauração, reconstrução e reparação ambiental das áreas atingidas em Minas Gerais e Espírito Santo. Para colocá-los em prática, foi criada a organização Fundação Renova, que utiliza de dotações financeiras feitas pelas empresas Samarco, BHP Biliton e Vale S/A ano a ano, conforme determinado na escritura pública de constituição e no TTAC (Termo de Transação e de Ajustamento de Conduta). Ao todo são 42 programas de reparação e compensação definidos, cada um com uma temática. A Fundação Renova é fiscalizada diretamente pela Promotoria de Justiça de Tutela de Fundações do Ministério Público de Minas Gerais, em Belo Horizonte. Além disso, ainda existe o Comitê Interfederativo (CIF), órgão do qual fazem parte o governo federal, os estados de Minas Gerais e do Espírito Santo, os municípios de Mariana, Rio Doce e Linhares e instituições públicas especializadas, como IBAMA, ANA, ICMBio, FUNAI, entre outras.

Em abril de 2016 foi criada a 0peração Áugias, do IBAMA, como estratégia para analisar o cumprimento das cláusulas 158 e 160 do TTAC, em atendimento à Deliberação CIF nº 11/2016, cujas principais objetivos são: i) realizar um diagnóstico completo do estado de degradação das áreas atingidas; ii) avaliar as intervenções que estão sendo realizadas pela Fundação Renova; e iii) monitorar as ações de recuperação durante todo o processo de restauração ambiental (Relatório Operação Áugias, 2017). No período de 13 a 23 de setembro de 2016, a segunda vistoria desta operação foi realizada em 78 pontos das áreas para recuperação e constatou-se que a maior parte das recomendações feitas anteriormente não foram cumpridas pela Renova, sendo que não houve intervenções de conservação de solo, de drenagem superficial e de contenção na maioria absoluta das áreas visitadas. 0 reflexo desta falta de ações foi claramente observado, dado que $92 \%$ dos pontos vistoriados apresentaram processos erosivos (Relatório Operação Áugias, 2017). Isso foi repassado à fundação e em março de 2017 foi realizada a terceira vistoria em 55 pontos, avaliando processos erosivos e colonização por espécies vegetais nativas, presença de espécies invasoras, de animais silvestres e de criação, do cercamento das áreas, das técnicas de conservação do solo, de drenagem superficial, entre outras e constatou-se de forma geral que a maior parte das recomendações feitas anteriormente não foi cumprida pela Fundação Renova. 
A quarta vistoria da 0peração Áugias foi feita em agosto e a quinta em outubro de 2017, reavaliando 113 pontos vistoriados nas fases anteriores, dando ênfase na avaliação da efetividade das ações emergenciais implementadas anteriormente visando dar início da fase de recuperação ambiental. A maioria dos processos avaliados apresentou melhora em relação às fases anteriores (Relatório Operação Áugias, 2017). Em maio de 2018 foi realizada uma vistoria das ações de recuperação das nascentes, que visa incrementar a quantidade e aprimorar a qualidade da água no curso hídrico ao longo da bacia do rio Doce. Constatou-se que muitas das áreas avaliadas precisam de maior frequência nas atividades de manutenção realizadas pela Fundação Renova, visto que muitas dessas áreas apresentaram situação irregular de acordo com o plano de recuperação a ser seguido.

A última vistoria feita pelo IBAMA, até o presente momento, foi realizada em junho de 2018 sendo a 0peração Áugias fase Argos etapa VI. Foram selecionados 60 tributários, onde a maioria (51 áreas) indica uma melhora na qualidade ambiental das áreas afetadas, como resposta das ações emergenciais implementadas pela Fundação Renova. Contudo, ainda existem áreas classificadas como negativas, resultado da inadequação ou ausência de intervenções essenciais, para a conclusão da fase emergencial após mais de dois anos do seu início (Relatório Operação Áugias VI, 2018).

Com relação aos danos socioambientais e humanos, a Fundação Renova também é responsável pela indenização das famílias acerca da interrupção no abastecimento e distribuição de água, dos danos gerais (perda de renda, bens materiais, imóveis residenciais e comerciais, propriedades rurais, etc.) e danos morais através do Programa de Indenização Mediada (PIM).

A Fundação Renova, disponibiliza, de forma pública, em seu site (www.fundaçaorenova.org) relatórios anuais e outros de acompanhamento sobre sua atuação e dados dos trabalhos realizados sobre a recomposição vegetal, acompanhamento social (indenizações financeiras e reconstrução de infraestrutura) recuperação de corpos hídricos e patrimônio. Em seu último relatório anual (Relatório CIF/ Anual de 2018), consta, entre outras informações, que o processo de reconstrução de vilas esta em andamento, mas ainda em fase documental e sem moradias construídas e que 312 famílias são atendidas com moradia temporária englobando cidades de Mariana (MG), Barra Longa (MG), Ouro Preto (MG), Acaiaca (MG), Santa Cruz do Escalvado (MG), Barueri (SP) e Souto Soares (BA). No que se refere a recuperação de comunidades e infraestruturas impactadas na região de Mariana e Barra Longa o processo encontrava-se, segundo o relatório de 2018, em andamento com alguma fases em atraso, com 692,6 km de acessos reformados , $212 \mathrm{~km}$ de cercamentos em propriedades rurais, 
119 residências e propriedades rurais reformadas, 28 comércios e 186 quintais e lotes e alguns equipamento públicos, como praças. As atividades aquícolas e pesqueira encontram-se ainda restritas. No que tange o programa de recuperação de áreas e recuperação de nascentes, o status é em andamento, tendo sido, em 2017, iniciado ações de recuperação de 511 nascentes e no ano de 2018 foram mapeadas 542 nascentes. Cabe ressaltar, que o relatório analisado (Relatório CIF/ Anual de 2018) apresenta informações sobre os programas realizados conforme exigido pelo Termo de Transação de Ajustamento de Conduta - TTAC, e tem suas ações com status em andamento.

\section{CONCLUSÃO}

Tendo em vista todos os impactos ambientais e sociais relatados neste trabalho e levando em conta que houve outros impactos que não foram registrados aqui e também os planos de recuperação e suas dificuldades de implementação, tanto pela magnitude dos danos como também por questões de falta de cumprimento dos prazos pelas empresas responsáveis, podemos concluir o quanto está sendo difícil resgatar toda a cena perdida com o desastre.

Mesmo constatadas melhorias em alguns dos aspectos avaliados, conforme apresentado em relatórios da 0peração Áugias, em comparação ao encontrado nas fases iniciais do processo de restauração, esses percentuais demonstram que as ações adotadas ainda se mostram insuficientes para garantir a plena contenção do rejeito depositado nas margens dos cursos d’água. Portanto, há necessidade de monitoramento constante sobre todos os pontos atingidos pelos rejeitos da barragem para garantir o cumprimento das ações pela Fundação Renova e avaliar a eficácia delas. Da mesma forma, as informações apresentadas em relatórios sobre cumprimento de ações previstas nos programas de recuperação ambiental e social, previstos no Termo de Transação de Ajustamento de Conduta, demonstram que há muitas ações a serem realizadas para restabelecimento ambiental e social da área impactada.

A devastação causada pelo rompimento da barragem do Fundão dizimou o Distrito de Bento Rodrigues, provocou mortes humanas, soterrou centenas de nascentes, contaminou rios importantes para manutenção da população e biomas, destruiu ecossistemas inteiros, além de causar prejuízos sociais e econômicos de difícil mensuração. Tais fatos deveriam promover maior comprometimento na recuperação da área afetada por partes da empresa responsável por essa tragédia. Assim como gerar maior cobrança e fiscalização, por parte dos órgãos fiscalizadores, sobre a manutenção e operação de barragem em todo território nacional. 


\section{REFERÊNCIAS BIBLIOGRÁFICAS}

BRASIL. Conselho Nacional de Meio Ambiente IBAMA. Resolução CONAMA 001, de 23 de janeiro de 1986. Estabelece as definições, as responsabilidades, os critérios básicos e as diretrizes gerais para uso e implementação da Avaliação de Impacto Ambiental como um dos instrumentos da Política Nacional do Meio Ambiente. Brasília, 23 de janeiro de 1986.

CÂMARA DE DEPUTADOS DE BRASÍLIA, Tragédia em Mariana: as causas do rompimento da barragem do Fundão Bloco 2. Rádio Câmara- Reportagem especial, 05 dezembro 2016. Disponível em: <http://www2.camara.leg.br/camaranoticias/radio/materias/REP0RTAGEM-ESPECIAL/520756-TRAGEDIA-EMMARIANA-AS-CAUSAS-D0-ROMPIMENT0-DA-BARRAGEM-D0-FUNDA0-BLOC0-2.html.> Acesso em: 05 agosto 2018.

FUNDAÇÃO RENOVA, Relatório anual de atividades, Ano 2018. Belo Horizonte, 2018. Disponível em:https://www.fundacaorenova.org/wp-content/uploads/2019/10/nocaminhodareparaca02019.pdf. Acesso em: 24 maio 2019.

GRUP0 DA FORÇA-TAREFA. Avaliação dos efeitos e desdobramentos do rompimento da Barragem de Fundão em Mariana-MG. $\quad$ Belo $\quad$ Horizonte, $2016 . \quad$ Disponível em: http://www.agenciaminas.mg.gov.br/ckeditor_assets/attachments/770/relatorio_final_ft_03_02_2016_15h5min.pd f>. Acesso em: 04 novembro 2017.

IBAMA. CIF determina prazo para indenização a atingidos pelo rompimento da barragem de Fundão. Notícias, 04 outubro 2017. Disponível em: <https://www.ibama.gov.br/noticias/422-2017/1209-cif-determina-prazo-paraindenizacao-a-atingidos-pelo-rompimento-da-barragem-de-fundao>. Acesso em: 19 março 2018.

IBAMA. Relatório Geral de Vistoria, Operação Áugias - Fase Argos - Etapa III e IV. Minas Gerais, 2017. Disponível em: https://www.ibama.gov.br/phocadownload/barragemdefundao/relatorios/2017-03-

16_Relatrio\%20Geral_Argos\%20III_FINAL.pdf. Acesso em: 25 abril 2018.

IBAMA. Relatório Geral de Vistoria, 0peração Áugias - Fase Olhos d'água II. Minas Gerais, 2018. Disponível em: https://www.ibama.gov.br/phocadownload/cif/notas-tecnicas/CT-FLOR/2018/cif-ct-flor-nt-2018-06-26\%20relatorio-olhos\%20-d\%20-agua-\%20II.pdf. Acesso em: 19 out 2018.

IBAMA. Laudo Técnico Preliminar- Impactos ambientais decorrentes do desastre envolvendo o rompimento da barragem de Fundão, em Mariana. Minas Gerais. 2015. Disponível em: 〈https://www.ibama.gov.br/phocadownload/barragemdefundao/laudos/laudo_tecnico_preliminar_Ibama.pdf $>$. Acesso em: 09 maio 2018.

LOPES, Luciano M. N. 0 rompimento da barragem de Mariana e seus impactos socioambientais. Sinápse Múltipla. Rio de Janeiro, 2016.

MUCELIN E BELLINI, Carlos Alberto e Marta. Lixo e Impactos Ambientais Perceptíveis no Ecossistema Urbano. Sociedade e Natureza, Uberlândia, 2008.

NUNES Rizzatto, A tragédia de Mariana e a responsabilidade civil do Estado. Migalhas. Coluna ABC do CDC $\begin{array}{llllll}\text { Correspondente } & \text { jurídico. } & 10 & \text { dezembro } & 2015 . & \text { Disponível }\end{array}$ <https://www.migalhas.com.br/ABCdoCDC/92,MI231291,31047A+tragedia+de+Mariana+e+a+responsabilidade+civil+ do+Estado>. Acesso em: 16 out 2018.

PAES. Cíntia. Processos e acordos marcam 30 meses do desastre da barragem de Mariana. Globo, Minas Gerais, 05 maio 2018. Disponível em: <https://gl.globo.com/mg/minas-gerais/desastre-ambiental-emmariana/noticia/processos-e-acordos-marcam-30-meses-do-desastre-da-barragem-de-mariana.ghtml . Acesso em: 08 julho 2018.

SIM0NETTI, Henrique. Estudo de Impactos Ambientais Gerados pelas Rodovias: Sistematização do Processo de Elaboração do EIA/RIMA. Universidade Federal do Rio Grande do Sul. Escola de Engenharia. 2010. 